13 - ARTIGO ORIGINAL

\title{
A influência do azul de metileno na prevenção da lesão pulmonar após isquemia-reperfusão intestinal ${ }^{1}$
}

The role of the methylene blue as a lung protector after intestinal ischemia and reperfusion

Fernando Hintz Greca ${ }^{2}$, Neuza Maria Ferraz de Mello Gonçalves ${ }^{3}$, Zacarias Alves de Souza Filho ${ }^{4}$, Antônio Pádua Gomes da Silva ${ }^{5}$, Wilson Hiroshi Mima ${ }^{6}$, Humberto Hideki Mima $^{7}$

1. Trabalho realizado na Disciplina de Técnica Operatória e Cirurgia Experimental da Pontifícia Universidade Católica do Paraná.

2. Professor Titular e Coordenador da Disciplina de Técnica Operatória e Cirurgia Experimental da PUC-PR. Professor Adjunto da Disciplina de Cirurgia Geral da UFPR. Doutor em Cirurgia UNIFESP-EPM.

3. Professora Titular da Disciplina de Bioquímica da PUC-PR. Doutora em Ciências Biológicas pela UFPR.

4. Professor Titular da Disciplina de Cirurgia Geral da UFPR e Professor Titular da Disciplina de Técnica Operatória e Cirurgia Experimental da PUC-PR. Doutor em Clínica Cirúrgica.

5. Professor da Disciplina de Patologia da PUC-PR.

6. Acadêmico de Medicina da UFPR, bolsista do programa de iniciação científica do CNPq.

7. Acadêmico de Medicina da PUC-PR.

\section{RESUMO}

OBJETIVO: Estudar a ação do azul de metileno como supressor da produção de radicais livres de oxigênio, atuando como receptor alternativo de elétrons na enzima xantina oxidase. MÉTODOS: Foram utilizados 32 ratos Wistar (Rattus norvegicus albinus, Rodentia mammalia) divididos em 2 grupos de 16 animais, os quais foram denominados grupos: experimento e controle. Ambos os grupos foram submetidos a laparotomia mediana e oclusão da artéria mesentérica cranial por 60 minutos. A reperfusão foi confirmada por meio da verificação do reaparecimento da pulsação na arcada mesentérica. Foi então administrado no grupo experimento $2 \mathrm{ml}$ de azul de metileno $1 \%$ estéril intraperitonealmente, enquanto que no grupo controle foi administrado solução salina isotônica estéril em mesmo volume e pela mesma via de administração. Após 4 horas de reperfusão, os animais foram sacrificados. Amostras dos pulmões foram obtidas para: análise histopatológica, avaliação do edema e para determinação da atividade da xantina oxidase.

RESULTADOS: O dano pulmonar encontrado no grupo controle foi superior ao encontrado no grupo experimento. Observou-se uma maior formação de edema nos pulmões do grupo controle. A atividade da xantina oxidase foi semelhante em ambos os grupos.

CONCLUSÃO: O azul de metileno diminui a lesão pulmonar após isquemia-reperfusão intestinal.

Descritores: Azul de metileno.Lesão de isquemia-reperfusão.Pulmão. 
PURPOSE: To study the role of methylene blue as an inibitor of superoxide production by xantine oxidase.

METHODS: Thirty two Wistar rats were divided in 2 groups of 16 animals: the control group and the experimental group. All the animals were submitted to a laparotomy for the occlusion of the cranial mesenteric artery during 60 minutes. The reperfusion was confirmed by the 'pulsation of the artery after releasing the temporary ligature. In the animals of the control group, $2 \mathrm{ml}$ of saline were injected in the peritoneal cavity and in the animals of the experimental group $2 \mathrm{ml}$ of methylene blue were injected in the peritoneal cavity. After reperfusion for 4 hours, the animals were sacrificed. The lungs were excised for histological studies, for evaluation of the pulmonary edema and the activity of xantine oxidase.

RESULTS: In the animals of the experimental group the inflammatory lesion of the lung was grater in the control group as well as the edema. The activity of the xantine oxidase was similar in both groups.

CONCLUSION: In rats, methylene blue can protect the lung against the toxic effects of oxygen radical in ischemia-reperfusion injuries.

Key words: Methylene blue. Ischemia-reperfusion injury. Lung.

\section{Introdução}

O envelhecimento da população está intimamente relacionado ao progresso da medicina e ao acesso das pessoas ao sistema de saúde, que em última análise é o reflexo do desenvolvimento sócio-econômico do país ${ }^{1}$.

Os avanços médicos não só propiciaram um aumento da sobrevida da população, mas contribuíram para que entidades nosológicas, tais como a isquemia mesentérica, pouco diagnosticada no passado, se tornasse freqüente nos dias de hoje ${ }^{1}$.

A isquemia mesentérica é uma das mais graves doenças circulatórias do trato gastrointestinal. Apresenta elevada morbidade e mortalidade. Tem como principais causas: tromboses intravasculares, fenômenos embólicos, oclusões mecânicas ou estados de choque. Dependendo do tempo de evolução, este processo pode evoluir para necrose intestinal ou restabelecimento da circulação com reperfusão do tecido isqüêmico ${ }^{1,2,3}$.

O processo de reperfusão gera, por mecanismos ainda discutidos na literatura, lesão em diversos órgãos, especialmente nos pulmões ${ }^{4}$. Vários estudos evidenciaram que a reperfusão pós-isquêmica ativa diversas cascatas inflamatórias que se inter-relacionam. Alterações metabólicas, decorrentes de oclusões arteriais agudas podem ser detectadas já durante o período isquêmico, porém são mais intensas após a revascularização do tecido. A identificação precoce desse processo é fundamental para a prevenção e diminuição de lesões orgânicas locais e sistêmicas na segunda fase, isto é, a fase de reperfusão tissular ${ }^{5}$.

Radicais livres de oxigênio desempenham um papel fundamental nas lesões pulmonares decorrentes da reperfusão de tecidos hipoperfundidos. Durante a fase isquêmica, ocorre grande liberação da enzima xantina oxidase, cuja ação leva a uma maior produção de radicais superóxido. Estes se relacionam com lesão da membrana alvéolo-capilar e conseqüente transudação, contribuindo assim para o aparecimento da síndrome da angústia respiratória do adulto (SARA). Além disso, os radicais livres de oxigênio relacionam-se com lesões em outros órgãos como coração, fígado, rim e cérebro ${ }^{6}$.

Em condições de estresse oxidativo, uma grande variedade de radicais livre de oxigênio é produzida, o que resulta em dano da membrana celular e aumento da permeabilidade endotelial a fluidos, macromoléculas e células inflamatórias ${ }^{7,8}$. 
Neutrófilos polimorfonucleares apresentam atividade importante no desenvolvimento de lesões pulmonares, que são dependentes da interação adesiva entre estes leucócitos e as células endoteliais. Os polimorfonucleares produzem mediadores químicos como radicais de oxigênio e proteases, que se relacionam a um aumento da permeabilidade endotelial e conseqüente penetração desses neutrófilos no interstício pulmonar, agravando a lesão tecidual?.

Radicais livres de oxigênio desencadeiam diretamente a ativação de polimorfonucleares, a sua adesão ao tecido endotelial e a outras células similares, bem como a quimiotaxia leucocitária, promovendo assim o desenvolvimento de lesão mediada por leucócitos, em tecidos submetidos à isquemia ${ }^{10}$.

Além da ação direta como efetores finais, os radicais livres de oxigênio apresentam atividade importante na fisiopatologia da lesão pulmonar aguda como mensageiros secundários. A expressão de moléculas adesivas e a produção de citocinas no pulmão são mediadas por estes radicais e relacionam-se à lesão inflamatória deste órgão ${ }^{9}$.

$\mathrm{O}$ azul de metileno inibe a produção de radicais superóxido por agir como um receptor alternativo de elétrons da xantina oxidase. Mais detalhadamente, pares de elétrons de cada oxidação enzimática são transferidos para o azul de metileno a partir do centro ferro-sulfúrico da xantina oxidase, onde o oxigênio molecular seria convertido em radicais superóxido. Desta forma, a formação destes radicais é inibida ${ }^{11}$.

Em ratos submetidos a sépsis decorrente de peritonite fecal por ligadura do ceco e perfuração, observa-se menor dano pulmonar, maiores níveis de pressão arterial e melhor função pulmonar nos animais tratados com azul de metileno, quando comparados àqueles de grupo controle ${ }^{15}$.

Além das ações mencionadas, o azul de metileno pode apresentar efeito protetor pulmonar por outros mecanismos, como inibição do óxido nítrico. Em coelhos submetidos a choque séptico induzido por inoculação de lipopolissacarídeos, observa-se que o azul de metileno administrado por via endovenosa restabelece os níveis de pressão arterial. Este efeito está relacionado à normalização dos níveis de óxido nítrico plasmático, cuja desregulação acarreta o desenvolvimento de hipotensão arterial e choque. Além da atividade de relaxamento da musculatura vascular, o óxido nítrico pode, quando em altos níveis, reagir com radicais superóxido e formar peroxinitrito, o qual apresenta propriedades citotóxicas ${ }^{16}$. Além disso, a decomposição do peroxinitrito promove severa atividade oxidante ${ }^{17}$.

O objetivo deste estudo é avaliar o efeito do azul de metileno, um inibidor da formação de radicais de oxigênio, na lesão pulmonar causada por isquemia-reperfusão intestinal, responsável direta pelo aumento de radicais livres circulantes.

\section{Métodos}

Este estudo obedeceu às normas de pesquisa com animais preconizadas pelo Colégio Brasileiro de Experimentação Animal (COBEA), instituição filiada ao International Council for Laboratory Animal Science.

Utilizaram-se 32 ratos machos (Rattus norvegicus albinus, Rodentia mammalia) da linhagem Wistar - PUC-PR, com idade que variou entre 100 e 130 dias, pesando 250 a 300 gramas.

Dividiu-se a amostra aleatoriamente em 2 lotes de 16 ratos cada: grupo controle e grupo experimento. Os animais permaneceram no Biotério Central da Pontifícia Universidade Católica do PR, mantidos em caixas padronizadas, com número máximo de 4 ratos por caixa, sob temperatura e luminosidade naturais, recebendo água potável e ração padrão comercial em regime livre até o início do experimento. 
Realizou-se anestesia geral, induzida com administração intramuscular de ketamina (60 $\mathrm{mg} / \mathrm{kg}$ ) e xilazina ( $10 \mathrm{mg} / \mathrm{kg}$ ).

Ambos os grupos foram submetidos à laparotomia mediana e oclusão da artéria mesentérica cranial por meio de uma ligadura temporária da mesma. Seguiu-se a síntese da parede abdominal em dois planos, o primeiro peritônio-músculo-aponeurótico; o segundo, o da pele, com chuleio contínuo, utilizando-se em ambos os planos, fio monofilamentar de náilon 3-0.

Após 60 minutos, reabriu-se a cavidade para a realização da reperfusão intestinal, confirmada por meio da verificação do reaparecimento da pulsação na arcada mesentérica. e mudança de coloração das alças do intestino delgado. Posteriormente, administrou-se, no grupo B, $2 \mathrm{ml}$ de azul de metileno estéril a $1 \%$ intraperitonealmente e, no grupo A, $2 \mathrm{ml}$ de solução salina isotônica estéril pela mesma via de administração. Seguiu-se novo fechamento da parede abdominal conforme técnica já descrita.

Decorridas 4 horas de reperfusão intestinal, os animais foram sacrificados. Procedeu-se a toracotomia mediana com isolamento e retirada dos pulmões, que imediatamente foram armazenados em cuba com gelo.

Os pulmões foram divididos em 3 partes: 1 segmento foi fixado em formalina a $10 \% \mathrm{e}$ encaminhado para estudo histopatológico, os 2 outros foram armazenados em cubas com gelo para estudo bioquímico e para avaliação do edema pulmonar.

Realizou-se avaliação da lesão pulmonar através de cortes obtidos a partir de toda extensão dos pulmões, corados com hematoxilina-eosina. Analisaram-se os seguintes parâmetros: edema intersticial e infiltração neutrofílica. Graduou-se o edema em: discreto (+) quando estiveram presentes somente alterações focais, moderado $(++)$ quando estiveram presentes alterações multifocais e intenso $(+++)$ quando estiveram presentes alterações difusas. Avaliou-se a infiltração neutrofílica pelo número de leucócitos presentes em aumento de 10 $\mathrm{X}$.

A partir da relação "peso-úmido" / "peso-seco", avaliou-se o edema pulmonar. Obteve-se o primeiro dado através da aferição da peça em balança digital analítica Scientech. As amostras foram secas em temperatura de $80^{\circ} \mathrm{C}$ por 24 horas de modo a permitir a medida do "pesoseco", 18 .

Determinou-se a atividade da enzima xantina oxidase por análise indireta através da quantificação do ácido úrico em $292 \mathrm{~nm}$ por espectofotometria ${ }^{19}$. Armazanou-se o segmento pulmonar destinado a esta análise em recipientes com gelo para a preservação enzimática. Realizou-se a homozeneização do material com a utilização do homogeneizador PotterElyhejem. A seguir, processou-se as etapas subsequentes para o isolamento da enzima com a utilização do banho maria Fanem e da centrífuga refrigerada Beckmann. Feito o isolamento, realizou-se a reação enzimática com a utilização do reativo xantina $0,20 \mathrm{mM} \quad(2,6$ dihydroxypurine - 99-100 \%, SIGMA®). Com a utilização do espectofotômetro de Beckmann, processou-se a análise espectofotométrica em $292 \mathrm{~nm}$.

Para a análise dos resultados foram utilizados os seguintes testes estatísticos: para avaliação do edema intersticial, utilizou-se o teste exato de Fisher; para análise da infiltração neutrofílica, adotou-se o teste não-paramétrico de Mann-Whitney e para a determinação da relação "peso-seco" / "peso-úmido" e avaliação da atividade da enzima xantina oxidase foi utilizado o teste t de Student para amostras independentes, levando-se em consideração a homogeneidade das variâncias. Fixou-se $\mathrm{p}=0,005$ ou $5 \%$ como nível de rejeição da hipótese de nulidade.

\section{Resultados}

Nenhum óbito ocorreu durante a realização do experimento. 
$\mathrm{Na}$ avaliação dos dois parâmetros histológicos, isto é edema intersticial e infiltração neutrofílica, verificamos que os animais tratados com o azul de metileno apresentaram um edema menor e uma reação leucocitária também menor, caracterizando assim um processo inflamatório menor (Figura 3).

Em relação ao edema intersticial o teste estatístico de Fisher demonstrou uma diferença significativa entre os dois grupos $(\mathrm{p}=0,0032)$. Observa-se na Tabela 1 que o grupo experimento apresenta um percentual maior de casos com grau discreto do que o grupo controle, um percentual menor de grau moderado do que o grupo controle e não apresenta casos de grau intenso.

Ao analisarmos a relação peso úmido/peso seco, observamos que ela foi significantemente maior no grupo controle que no grupo experimento, comprovado estatisticamente pelo teste $t$ de Student, $(\mathrm{p}<0,05)$, o que corrobora com a análise qualitativa do parâmetro "edema intersticial", realizada no estudo histológico (Figura 1 e Tabela 2).

Em relação ao infiltrado neutrofílico, o teste de Mann-Withney indicou que existe diferença estatisticamente significante entre os grupos estudados, visto que o número de neutrófilos foi significantemente maior no grupo controle que no grupo experimento $(\mathrm{p}<0,0001)$ (Figura 2$)$. $\mathrm{Na}$ avaliação da atividade da enzima xantina oxidase, de forma indireta por aferição da concentração de ácido úrico, verificou-se que a atividade da enzima estava presente e era semelhante nos dois grupos estudados. Estes dados foram demonstrados pelo teste $\mathrm{t}$ de Student para amostras independentes, levando-se em consideração a homogeneidade das variâncias. Não houve evidência de que os grupos sejam diferentes em relação ao nível de ácido úrico $(\mathrm{p}=0,796)$.

TABELA 1 - Estudo histológico para avaliação do edema pulmonar no grupo controle e no grupo experimento.

\begin{tabular}{lcc}
\hline Edema intersticial* & Grupo Experimento & Grupo Controle \\
\hline Grau 1 - Discreto & $11(68,75 \%)$ & $2(12,50 \%)$ \\
Grau 2 - Moderado & $5(31,25 \%)$ & $12(75,00 \%)$ \\
Grau 3 - Intenso & $0(0,00 \%)$ & $2(12,50 \%)$ \\
\hline Total & 16 & 16 \\
\hline
\end{tabular}

(*) As classificações moderado e intenso foram agrupadas para a aplicação do teste. 


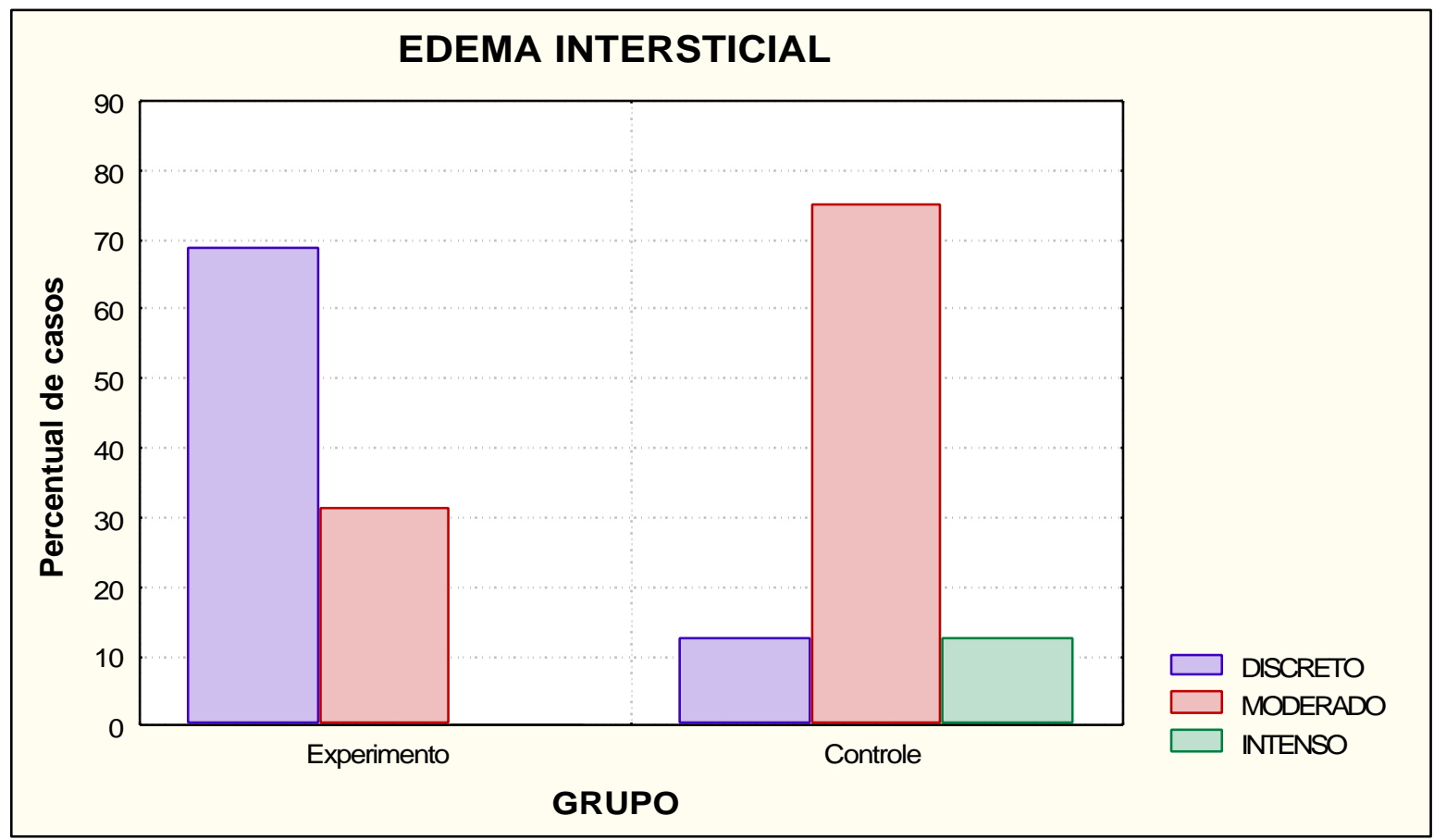

FIGURA 1 - Percentual de casos de edema intersticial discreto, moderado e intenso nos grupos experimento e controle.

TABELA 2 - Média dos valores e desvio padrão do número de neutrófilos, da relação peso úmido/peso seco e da atividade da enzima xantina oxidase através da concentração de ácido úrico tissular.

\begin{tabular}{c|ccc}
\hline & $\begin{array}{c}\text { Grupo } \\
\text { Experimento n=16 }\end{array}$ & $\begin{array}{c}\text { Grupo Controle } \\
\mathbf{n = 1 6}\end{array}$ & Valor de p \\
\hline & $\begin{array}{c}\text { Média } \pm \text { desvio } \\
\text { padrão }\end{array}$ & $\begin{array}{c}\text { Média } \pm \text { desvio } \\
\text { padrão }\end{array}$ & \\
$\begin{array}{c}\text { Número de } \\
\text { neutrofilos }\end{array}$ & $10,50 \pm 2,66$ & $28,75 \pm 3,89$ & $<\mathbf{0 , 0 0 0 1}^{*}$ \\
$\begin{array}{c}\text { Relação peso } \\
\text { úmido/peso seco }\end{array}$ & $4,91 \pm 0,41$ & $6,15 \pm 0,21$ & $\mathbf{0 , 0 0 0 1}^{\text {* }}$ \\
\hline $\begin{array}{c}\text { Ácido úrico }(\mathrm{u} / \mathrm{mg} \\
\text { de proteína }\end{array}$ & $2,31 \pm 0,17$ & $2,32 \pm 0,18$ & 0,7966 \\
\hline
\end{tabular}




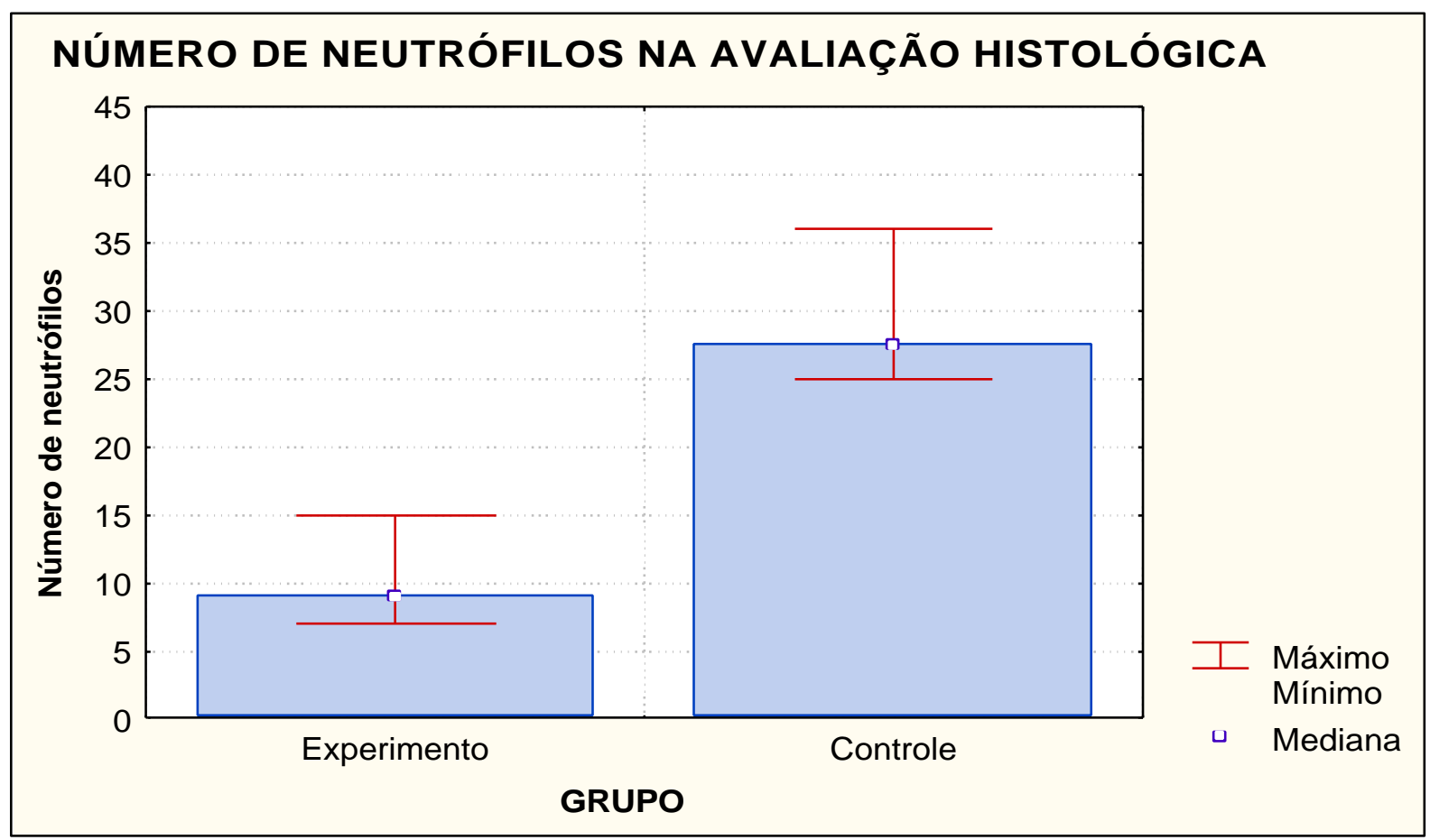

FIGURA 2 - Média do número de leucócitos neutrófilos encontrados no grupo experimento e no grupo controle.

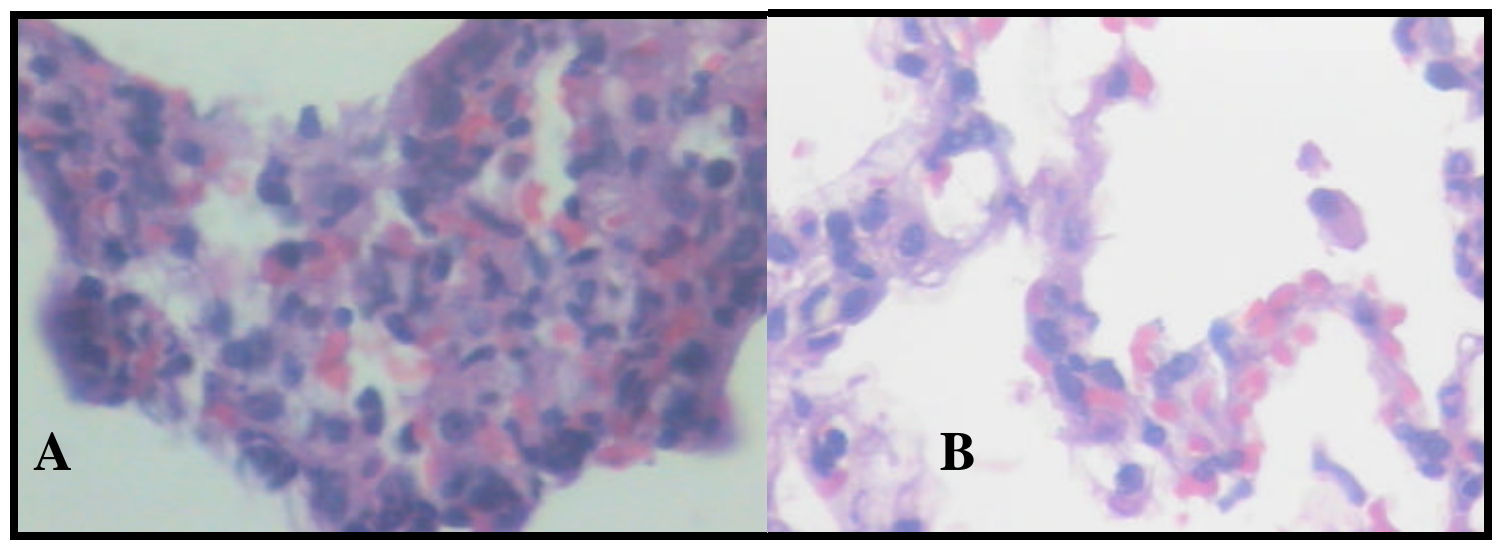

FIGURA 3 - Fotomicrografias do corte histológico de pulmão de animal do grupo controle (A) e de animal do grupo experimento (B) submetido a tratamento com azul de metileno, demonstrando acentuado edema e importante reação leucocitária no grupo controle em relação ao grupo experimento (HE - 400x). 


\section{Discussão}

A isquemia mesentérica aguda acarreta altas taxas de mortalidade, variando de 60 a $100 \%$. Sua causa mais freqüente é a embolização da artéria mesentérica superior (50\%), seguida pela trombose da mesma artéria em aproximadamente $25 \%$ dos casos ${ }^{3}$.

Em nosso estudo, a oclusão da artéria mesentérica cranial em ratos promoveu na totalidade dos casos isquemia intestinal, observada pela coloração azulada da víscera após 60 minutos de interrupção do fluxo arterial.

Atici e col (2003) demonstraram os efeitos deletérios da isquemia-reperfusão intestinal sobre a capacidade regenerativa do fígado. Além deste, diversos órgãos também são afetados, tendo especial participação os pulmões ${ }^{4}$.

A análise histopatológica realizada neste experimento mostrou importante lesão pulmonar no grupo controle. Observou-se uma maior infiltração neutrofílica nos animais grupo controle quando se comparou com o experimento.

A lesão pulmonar também pode ser observada pelo importante edema pulmonar encontrado no grupo controle na avaliação da relação "peso-úmido" / "peso-seco".

O principal mecanismo envolvido na gênese da lesão pulmonar é a grande liberação de xantina oxidase durante o período de isquemia intestinal. Durante a reperfusão, o retorno da oferta de oxigênio leva a produção de grande quantidade de radicais superóxido. Estes levam ao desenvolvimento da Síndrome da Angústia Respiratória do Adulto pela lesão da membrana alvéolo-capilar com posterior formação de transudato pulmonar ${ }^{6}$.

Em nosso estudo, quantificamos a atividade da enzima xantina oxidase de forma indireta pela formação do ácido úrico. Métodos mais sensíveis já foram propostos por outros autores como Beckman que preconizou a utilização de uma medida fluorométrica que é 100 a 500 vezes mais sensível que o método anterior ${ }^{21}$. Entretanto, encontramos grande dificuldade na realização desta metodologia o que tornou inviável a sua utilização.

A aferição direta dos radicais de oxigênio seria o método mais fidedigno na avaliação de processos sistêmicos que levam a sua formação. Todavia, custos elevados tornam a execução desse método quase que impraticável.

A análise bioquímica deste estudo mostrou o êxito na obtenção da liberação da xantina oxidase no pulmão de ambos os grupos. Os valores obtidos pela espectrofotometria mostraram importante atividade biológica da enzima em todos os animais do experimento.

Isto corrobora com a teoria de que em ambos os grupos a atividade da xantina oxidase se mantém, mesmo com o uso do azul de metileno, pois eles sofreram o mesmo estresse isquêmico. Entretanto, o grupo experimento apresenta menor lesão pulmonar, pois o azul de metileno funciona como um receptor dos elétrons provenientes da reação enzimática catalizada pela enzima. No grupo controle, o oxigênio é que recebe esses elétrons levando a formação de radicais livres que atuam no processo de lesão sistêmica.

Salaris e col. em 1991 estudaram a utilização do azul de metileno como um inibidor da geração de radicais de oxigênio pela ação da enzima xantina oxidase. Demonstraram que pares de elétrons de cada oxidação enzimática são transferidos para o centro ferro-sulfúrico do azul de metileno.

No grupo experimento em que se utilizou o azul de metileno, observou-se um menor índice de lesão pulmonar pela menor seqüestração de neutrófilos na análise histológica. Também observou-se pouca formação de edema intersticial quando se comparou com o grupo controle. A análise da relação "peso-úmido" / "peso-seco" mostrou maior formação de edema pulmonar nos animais onde se administrou solução salina isotônica. 


\section{Conclusão}

O azul de metileno, quando utilizado na prevenção da lesão pulmonar pela isquemiareperfusão intestinal em ratos, apresenta excelentes resultados na diminuição do seqüestro neutrofílico e na menor formação de edema pulmonar.

\section{Referências}

1. Biondo-Simões MLP, Greca FH, Ioshi SO, Chin EWK, Kimura LY, Lemos MC. Efeitos da isquemia e reperfusão intestinal na cicatrização de anastomoses do intestino delgado: estudo experimental em ratos. Acta Cir Bras 2001;16(supl.2):9-15.

2. Edward MS, Cherr GS, Craven TE, Olsen AW, Plonk GW, Geary, RL, Ligush JL, Hansen KJ. Acute occlusive mesenteric ischemia: surgical management and outcomes. Ann Vasc Surg 2003;17(1):72-9.

3. Lock, G. Acute mesenteric ischemia: classification, evaluation and therapy. Acta Gastroenterol Belg 2002;65(4):220-5.

4. Galili Y, Ben,Abraham R, Weinbroum A, Marmur S, Iaina A, Volkman Y, Peer G, Szold O, Soffer D, Klausner J, Rabau M, Kluger Y. Methylene blue prevents pulmonary injury after intestinal ischemiareperfusion. J Trauma 1998;222:5.

5. Haimovic H. Metabolic complications of acute arterial occlusions. J Cardiovasc Surg 1979;20(4):349-57.

6. Mc Cord JM. . Oxygen-derived free radicals in postischemic tissue injury. N Engl J Med. 1985;312(3):15963.

7. Mc Quaid KE, Keenan AK. Endothelial barrier dysfunction and oxidative stress: role for nitric oxide? Exp Physiol 1997;82(2):369-76.

8. Cohen SM, Siddiqi, FA, Darakchiev B, Fantini GA, Hairi RJ, Barie PS. Attenuation of acute lung injury caused by hind-limb ischemia-reperfusion injury by butylactone anti-inflammatory agent FL 1003. J Trauma 1997;43(2):247-52.

9. Ishii Y, Yamasawa H, Kitamura S. Role of oxidants in adhesion molecule expression and cytokine production. Nihon Kobu Shikkan Gakkai Zasshi 1996;34(supl):126-30.

10. Fraticelli A, Serrano Jr. CV, Bochner BS, Capogrossi MC, Zweier JL. Hydrogen peroxide and superoxide modulate leukocyte adhesion molecule expression and leukocyte endothelial adhesion. Biochim Biophys Acta 1996;1310(3):251-9.

11. Salaris SC, Babbs CF, Voorhees WD. Methylene blue as an inhibitor of superoxide generation by xanthine oxidase: a potencial new drug for the attenuation of ischemia/reperfusion injury. Biochem Pharmacol 1991;42:499-506.

12. Kelner MJ, Bagnell R, Hale B, Alexander NM. Methylene blue competes with paraquat for reduction by flavo-enzymes resulting in decreased superoxide production in the presence of heme proteins. Arch Biochem Biophys 1988;262 (2):422-6.

13. Kelner MJ, Bagnell R, Hale B, Alexander NM. Potencial of methylene blue to block oxygen radical generation in reperfusion injury. Basic Life Sci 1988;49:895-8.

14. Jarasch ED, Bruder G, Heid HW. Significance of xanthine oxidase in capillary endothelial cells. Acta Physiol Scand Suppl 1986;548:39-46.

15. Galli Y, Kluger Y Mianski Z, Iaiana A, Wollman Y, Marmur S, Soffer D, Chernikosky T, Klausner JP, Rabau. Methylene blue: a promising treatment modality in sepsis induced by bowel perforation. Eur Surg Res 1997;29:390-5.

16. Keaney JF, Puyana JC, Francis S, Loscalzo JF, Stamler JS, Loccalzo J. Methylene blue reverses endotoxininduced hypotension. Circ Res 1994;74:1121-5.

17. Beckman JS, Beckman TW, Chen J, Marshall PA, Freeman BA. Apparent hydroxyl radical production by peroxynitrite: implications for endothelial injury from nitric oxide and superoxide. Proc Natl Acad Sci USA. 1990;87(4):1620-4.

18. Stephens Ke, Ishizaka A, Lamick JW, Raffin TA. Tumor necrosis factor causes increased pulmonary permeability and edema. Am Rev Resp Dis 1988;137(6):1364-70.

19. Hashimoto S. A new spectrophotometric assay method of xanthine oxidase in crude tissue homogenate. Anal Biochem 1974;62:426.

20. Atici AE, Kaya Y, Coskun T, Aral E, Var A. Intestinal ischemia-reperfusion impairs liver regeneration after partial hepatectomy in rats. Hepagastroenterology 2003;50(51):661-5.

21. Beckman JS, Parks DA, Pearson JD, Marshall PA, Feeman BA. A sensitive fluorometric assay for measuring xanthine dehydrogenase and oxidase in tissues. Free Radic Biol Med 1989;6(6):607-15. 
Correspondência:

Fernando Hintz Greca

Av. Visconde de Guarapuava, 5087/1401

80240-010 Curitiba - PR

fernando.greca@bbs2.sul.com.br

Recebimento: 23/04/2004

Revisão: 19/05/2004

Aprovação: 07/06/2004

Conflito de interesse: nenhum

Fonte de financiamento: nenhuma

Como citar este artigo:

Greca FH, Gonçalves NM, Souza Filho ZA, Silva APG, Mima WH, Mima HH. A influência do azul de metileno na prevenção da lesão pulmonar após isquemia-reperfusão intestinal. Acta Cir Bras [serial online] 2004 JulAg;19(4). Disponível em URL: http://www.scielo.br/acb [também em CD-ROM]. 